\title{
HUBUNGAN BEBAN KERJA FISIK DENGAN KELUHAN MUSKULOSKELETAL PADA PERAWAT DI RUANG LELY 1 DAN 2 RSUD BULELENG
}

\author{
Luh Dea Pratiwi ${ }^{1}$, I Kadek Saputra ${ }^{2}$, Meril Valentine Manangkot ${ }^{3}$ \\ ${ }^{1}$ Mahasiswa Program Studi Sarjana Keperawatan dan Profesi Ners Fakultas Kedokteran Universitas Udayana \\ ${ }^{2}$ Departemen Keperawatan Gawat Darurat, Program Studi Sarjana Keperawatan dan Profesi Ners \\ Fakultas Kedokteran Universitas Udayana \\ ${ }^{3}$ Departemen Keperawatan Intensif, Program Studi Sarjana Keperawatan dan Profesi Ners Fakultas Kedokteran \\ Universitas Udayana \\ Alamat korepondensi: deapratiwi04@gmail.com
}

\begin{abstract}
ABSTRAK
Perawat merupakan profesi tenaga kesehatan terbanyak di rumah sakit yang harus menangani dan merawat pasien selama 24 jam dengan melakukan asuhan keperawatan melalui tindakan manual material handling seperti perawatan langsung dan memindahkan pasien secara manual. Manual material handling berisiko menimbulkan beban kerja fisik yang ditandai dengan adanya nyeri di daerah otot yang disebut dengan keluhan muskuloskeletal. Tujuan penelitian ini adalah untuk mengetahui hubungan beban kerja fisik dengan keluhan muskuloskeletal pada perawat di ruang Lely 1 dan 2 RSUD Buleleng. Penelitian ini merupakan deskriptif korelasional dengan rancangan penelitian cross sectional. Sampel dalam penelitian ini berjumlah 25 responden yang dipilih dengan metode probability sampling yaitu total sampling. Instrumen penelitian yang digunakan dalam penelitian ini yaitu cardiovascular load dengan menggunakan ten pulse method untuk mengetahui beban kerja fisik dan Nordic Body Map untuk menilai keluhan muskuloskeletal. Hubungan beban kerja fisik dengan keluhan muskuloskeletal pada perawat dianalisis menggunakan uji korelasi Spearman Rank karena data tidak berdistribusi normal. Hasil penelitian menunjukkan bahwa sebagian besar responden memiliki beban kerja fisik kategori sangat ringan $(84 \%)$ dan keluhan muskuloskeletal kategori rendah $(84 \%)$. Uji Spearman Rank menunjukkan adanya hasil yang signifikan dengan nilai p yaitu $0,000, r=0,727$. Kesimpulan dalam penelitian ini yaitu ada hubungan yang positif antara beban kerja fisik dengan keluhan muskuloskeletal pada perawat di ruang Lely 1 dan 2 RSUD Buleleng. Berdasarkan hasil penelitian, disarankan untuk mempertahankan kondisi lingkungan kerja yang nyaman sehingga meminimalisir munculnya keluhan muskuloskeletal.
\end{abstract}

Kata kunci: Beban kerja fisik, keluhan muskuloskeletal, perawat

\begin{abstract}
Nurses are the most health professions in the hospital that have to handle and treat the patients for 24 hours and give nursing care by using manual material handling. Manual material handling has risk creates a physical workload that is characterized by pain in muscle area called as musculoskeletal disorders. This study aimed to determine the correlation of physical workload and musculoskeletal disorders among nurses in Lely 1 and 2 wards of Buleleng Hospital. This study was descriptive correlational with a cross sectional study design. The sample of this study was 25 respondents who were selected by probability sampling method with total sampling. The research instruments that used in this study was cardiovascular load using ten pulse method to measure the physical workload and Nordic Body Map to measure the musculoskeletal disorders. The correlation of physical workload and musculoskeletal disorders among nurses was analyzed by using Spearman Rank because data not distributed normally. The results showed that most of respondents had very mild physical workload categories $(84 \%)$ and low category musculoskeletal disorders (84\%). Spearman Rank test showed a significant result with $\mathrm{p}$-value $=0,000, r=0,727$. In conclusion, there is a positive relationship between physical workload and musculoskeletal disorders among nurses in the Lely 1 and 2 wards of Buleleng Hospital. Based on the results of this study, it is recommended to maintaining environment so that musculoskeletal disorder not increase
\end{abstract}

Keywords: Musculoskeletal disorder, nurses, physical workload. 


\section{PENDAHULUAN}

Rumah sakit menjadi tempat pelayanan kesehatan yang diharapkan mampu memberikan pelayanan kesehatan secara komprehensif dan bermutu melalui tenaga kesehatan yang bekerja secara kompleks (Kemenkes, 2013). Perawat merupakan profesi tenaga kesehatan terbanyak di rumah sakit yang harus menangani dan merawat pasien selama 24 jam yang dikelompokan berdasarkan shift. Kegiatan yang dilakukan perawat dalam melakukan asuhan keperawatan menerapkan tindakan manual material handling (Elyas, 2012).

\section{Manual Material Handling}

(MMH) merupakan sebuah aktivitas memindahkan beban oleh tubuh secara manual dalam rentang waktu tertentu yang dapat menimbulkan masalah pada area muskuloskeletal jika tidak dilakukan secara prinsip ergonomi yang benar (OSHA, 2013). MMH menggunakan tenaga manusia untuk mengangkat, mendorong, menarik, mengangkut, menaikkan, dan menurunkan suatu objek tertentu (Elyas, 2012). Pada perawat, kegiatan MMH meliputi mobilisasi pasien, melakukan perawatan secara langsung yang membutuhkan kegiatan fisik secara statis, dan pengulangan aktivitas yang berlebihan dengan posisi tubuh yang salah (Kurniawidjaja, Purnomo, Maretri \& Pujiriani, 2014). MMH merupakan kategori kerja berat, sehingga berisiko menimbulkan beban kerja khususnya secara fisik (Sudiajeng, 2014).

Menurut Kasmarani (2012) beban kerja merupakan masalah yang timbul dari interaksi antara tuntutan tugas-tugas dan lingkungan kerja secara terus-menerus. Beban kerja pada perawat adalah segala sesuatu yang dikerjakan berdasarkan fungsi utamanya sebagai perawat, tugas tambahan yang dikerjakan, jumlah pasien yang harus dirawat dan jam kerja yang berlangsung setiap hari (Nursalam, 2013). Keluhan muskuloskeletal merupakan keluhan yang dirasakan sebagai akibat dari kumpulan benturan kecil maupun benturan besar yang terakumulasi secara terus- menerus dalam jangka waktu yang lama sehingga menimbulkan rasa nyeri dan rasa tidak nyaman pada otot, tulang, dan sendi (Tarwaka, 2014). Penelitian yang dilakukan oleh Habibi, Reza, dan Hsanzadeh (2015) pada 247 perawat yang bekerja di Rumah Sakit Alzahra di Iran menunjukan bahwa terdapat hubungan antara beban kerja fisik dengan terjadinya tingkat keluhan muskuloskeletal berupa keluhan pada leher, punggung, tangan, dan kaki dengan nilai $\mathrm{p}<0,001$.

Hasil studi pendahulan yang dilakukan peneliti di ruang Lely 1 dan 2 RSUD Buleleng pada 10 perawat menunjukan bahwa terdapat keluhan muskuloskeletal rendah sebanyak 60\% (6 perawat) dan keluhan muskuloskeletal sedang sebanyak $40 \%$ (4 perawat) yang dikaji menggunakan kuesioner Nordic Body Map. Untuk beban kerja terdapat $30 \%$ (3 perawat) perawat memiliki beban kerja sedang dan $70 \%$ (7 perawat) memiliki beban kerja rendah yang menggunakan metode perhitungan beban kardiovaskular dengan rumus Cardiovasculair Load (\%CVL) melalui pengukuran denyut nadi.

\section{METODE PENELITIAN}

Penelitian ini merupakan jenis penelitian deskriptif korelasional yaitu menilai hubungan antara beban kerja fisik terhadap keluhan muskuloskeletal dengan rancangan penelitian cross sectional karena peneliti hanya mengamati kejadian pada akhir shift perawat bekerja.

Penelitian ini dilakukan di RSUD Buleleng. RSUD Buleleng yang beralamatkan di Jalan Ngurah Rai No. 30, Singaraja, Buleleng. RSUD Buleleng telah memperoleh akreditasi Paripurna pada tahun 2016. Terdapat 30 ruang rawat inap maupun rawat jalan. Salah satu ruang inap di RSUD Buleleng ialah ruang Lely 1 dan 2. Peneliti memilih ruang Lely 1 dan 2 karena menurut data Dinas Kesehatan 
Buleleng tahun 2017 pasien rawat inap meningkat dari tahun 2013-2017.

Teknik sampling yang digunakan dalam penelitian ini merupakan penarikan populasi dengan teknik total sampling. Jenis data yang dikumpulkan adalah data primer dan data sekunder. Data primer merupakan data yang langsung didapat dari responden melalui pengisian kuesioner NBM dan melakukan pengukuran denyut arteri radialis atau ulnaris dengan menggunakan ten pulse method yang dimasukan kedalam rumus cardiovasculair load (\%CVL). Data sekunder diperoleh peneliti untuk mengetahui jumlah perawat yang bekerja di ruang Lely 1 dan 2 RSUD Buleleng.

Metode pengukuran denyut nadi menggunakan penghitungan manual pada arteri radialis atau arteri ulnaris dengan menggunakan ten pulse method untuk menghitung denyut nadi istirahat dan denyut nadi kerja. Denyut nadi istirahat diukur sebelum perawat melakukan kegiatan dan denyut nadi kerja dinilai segera setelelah perawat selesai melakukan pekerjaan. Denyut nadi maksimum pada perempuan ialah 200x/menit, sedangkan pada laki-laki ialah 220x/menit. Kemudian hasil dari penghitungan tersebut dimasukan kedalam rumus cardiovasculair load untuk mengetahui kategori beban kerja fisik. Sedangkan untuk keluhan muskuloskeletal menggunakan kuesioner Nordic Body Map (NBM) yang telah dikategorikan berdasarkan keluhan keluhan pada 28 bagian tubuh .

\section{HASIL PENELITIAN}

Tabel 1

Karakteristik Responden Berdasarkan Usia $(\mathrm{n}=25)$

\begin{tabular}{llcc}
\hline & Variabel & Frekuensi (n) & Persentase (\%) \\
\hline Usia & & 28 \\
\hline $21-25$ tahun & 7 & 36 \\
\hline $26-30$ tahun & 9 & 24 \\
\hline $31-35$ tahyn & 6 & 12 \\
\hline $36-40$ tahun & 3 & $\mathbf{1 0 0}$ \\
\hline Total & $\mathbf{2 5}$ &
\end{tabular}

Berdasarkan Tabel 5.1 didapatkan hasil tertinggi berada pada rentang $26-30$ bahwa rentang usia dari 25 responden tahun sebanyak 9 orang (36\%) didapatkan frekuensi rentang usia

Tabel 2

Karakteristik Responden Berdasarkan Jenis Kelamin $(\mathrm{n}=25)$

\begin{tabular}{clcc}
\hline & Variabel & Frekuensi (n) & Persentase (\%) \\
\hline Jenis Kelamin & & & 0 \\
\hline & Laki laki & 0 & 100 \\
\hline Perempuan & 25 & $\mathbf{1 0 0}$ \\
\hline
\end{tabular}

Tabel 2 dapat dilihat distribusi responden berdasarkan jenis kelamin yaitu berjenis kelamin laki-laki tidak ada dan responden berjenis kelamin perempuan sebanyak 25 orang $(100 \%)$. 
Tabel 3

Karakteristik Responden Berdasarkan Beban Kerja Fisik ( $\mathrm{n}=25)$

\begin{tabular}{ccc}
\hline \multicolumn{1}{c}{ Variabel } & Frekuensi (n) & Persentase (\%) \\
\hline Beban Kerja Fisik & & \\
\hline Sangat ringan & 21 & 84 \\
\hline Ringan & 3 & 12 \\
\hline Berat & 1 & 4 \\
\hline Total & $\mathbf{2 5}$ & $\mathbf{1 0 0}$ \\
\hline
\end{tabular}

Tabel 3 dapat disimpulkan sebagian sangat ringan dengan persentase $84 \%(21$ perawat di Ruang Lely 1 dan 2 memiliki orang). tingkat beban kerja fisik pada kategori

Tabel 4

Karakteristik Responden Berdasarkan Keluhan Muskuloskeletal $(\mathrm{n}=25)$

\begin{tabular}{ccc}
\hline Variabel & Frekuensi (n) & Persentase (\%) \\
\hline Keluhan Muskuloskeletal & & \\
\hline Rendah & 21 & 84 \\
\hline Sedang & 3 & 12 \\
\hline Tinggi & 1 & 4 \\
\hline Total & $\mathbf{2 5}$ & $\mathbf{1 0 0}$ \\
\hline
\end{tabular}

Tabel 4 dapat disimpulkan sebagian perawat di Ruang Lely 1 dan 2 memiliki tingkat keluhan muskuloskeletal pada kategori rendah dengan persentase $84 \%$ (21 orang).

Tabel 5

Hasil Uji Kolerasi Bivariat Spearman Rank.

\begin{tabular}{|c|c|c|c|c|}
\hline & Variabel & & $\mathbf{r}$ & P value \\
\hline $\begin{array}{l}\text { Beban Kerja } \\
\text { Muskuloskeletal }\end{array}$ & Fisik dengan & Keluhan & 0,727 & 0,000 \\
\hline
\end{tabular}

Berdasarkan tabel 5 dapat diketahui bahwa $\mathrm{p}$ value $=0,000(<0,05)$ yang berarti $\mathrm{H}_{0}$ ditolak. Sehingga ada hubungan antara beban kerja fisik dengan keluhan muskuloskeletal. Arah hubungan bernilai positif yang berarti hubungan kedua variabel bersifat searah, dengan demikian jika beban kerja fisik meningkat, maka keluhan muskuloskeletal juga mengalami peningkatan. Dilihat dari analisis kuat hubungan antara kedua variabel yang ditentukan oleh nilai $r$ sebesar 0,727 . Pada rentang nilai tersebut maka hubungan bernilai kuat.

\section{PEMBAHASAN}

Beban kerja fisik merupakan seluruh aktifitas yang dilakukan oleh seorang perawat selama melakukan asuhan keperawatan dalam suatu unit pelayanan kesehatan. Kategori ringan dan berat suatu beban kerja dipengaruhi oleh lingkungan kerja, tingkat ketergantungan pasien, dan jumlah perawat yang tersedia dalam satu shift (Marquish \& Huston, 2010).

Hasil penelitian menunjukan bahwa sebagian besar perawat di Ruang Lely 1 dan 2 memiliki beban kerja dengan kategori sangat ringan sebanyak 21 perawat $(84 \%)$, kategori ringan sebanyak 3 perawat (12\%), dan beban kerja fisik kategori berat 1 perawat (4\%). Keluhan muskuloskeletal merupakan gangguan yang mempengaruhi fungsi normal otot 
rangka akibat paparan yang berulang dari berbagai faktor risiko di tempat kerja. Muskuloskeletal menyebabkan masalah kerja yang signifikan akibat peningkatan kompensansi biaya kesehatan, penurunan produktivitas, dan rendahnya kualitas hidup (Sekaaram, 2017).

Hasil penelitian ini menunjukan bahwa sebagian besar perawat di Ruang Lely 1 dan 2 mengalami keluhan muskuloskeletal pada kategori rendah yang berjumlah 21 perawat $(84 \%)$.

Hasil penelitian ini menunjukan bahwa terdapat hubungan yang bermakna antara beban kerja fisik dengan keluhan muskuloskeletal pada perawat di Ruang Lely 1 dan 2 RSUD Buleleng. Kekuatan hubungan yang terbentuk mengidentifikasikan adanya hubungan yang kuat dengan interpretasi hubungan bersifat positif yang berarti semakin tinggi nilai beban kerja fisik, maka keluhan muskuloskeletal pada perawat di Ruang Lely 1 dan 2 akan semakin meningkat.

Beban kerja fisik yang berlebihan akan mengakibatkan stres kerja secara fisik berupa merupakan keluhan muskuloskeletal. Keluhan muskuloskeletal pada umumnya terjadi karena kontraksi otot berlebihan akibat pemberian beban kerja yang terlalu berat dengan durasi pembebanan yang panjang (Siswiyanti, 2011). Beban kerja fisik adalah kerja yang memerlukan energi fisik pada otot manusia yang akan berfungsi sebagai sumber tenaga.

Setiap manusia memiliki beban kerja masing-masing untuk lakilaki maksimal $40 \mathrm{~kg}$ beban yang dapat diangkat dan untuk perempuan separuh dari beban kerja laiki-laki yakni $20 \mathrm{~kg}$, jika penggunaan otot dalam durasi lebih dari 1 jam maka akan mempercepat timbulnya keluhan muskuloskeletal, dalam Marinawati (2016). Keluhan otot tidak akan terjadi apabila kontraksi otot hanya berkisar 15\%-20\% dari kekuatan otot maksimum. Namun apabila kontraksi otot melebihi $20 \%$ peredaran darah ke otot akan berkurang dan suplai oksigen ke otot menurun, sehingga terjadi penimbunan asam laktat yang menimbulkan rasa nyeri pada otot (Tarwaka, 2014).

Hasil penelitian yang dilakukan oleh Indriasari, Harmilah dan Maryana (2017) juga menyatakan bahwa terdapat hubungan antara beban kerja dengan keluhan low back pain pada perawat di RSUD Kota Yogyakarta. Dalam penelitian tersebut, low back pain merupakan bagian dari keluhan muskuloskeletal. Hasil penelitian ini berbeda dengan penelitian yang dilakukan oleh Desriana \& Febi (2017) bahwa tidak terdapat, karena beban kerja perawat berada pada kategori ringan dan tidak banyak melakukan aktivitas berulang.

\section{KESIMPULAN DAN SARAN}

Berdasarkan hasil penelitian, dapat disimpulkan bahwa rerata skor beban kerja fisik pada perawat di Ruang Lely 1 dan 2 sebesar 20,84. Sebagian besar beban kerja fisik pada perawat berada pada kategori sangat ringan dengan persentase $84 \%$ (25 orang). Rerata skor keluhan muskuloskeletal pada perawat di Ruang Lely 1 dan 2 sebesar 40,44. Sebagian besar keluhan muskuloskeletal pada perawat berada pada kategori rendah dengan persentase sebesar $84 \% \quad(25$ orang).

Hasil uji korelasi Spearman Rank menunjukkan bahwa terdapat hubungan yang bermakna antara beban kerja fisik dengan keluhan muskuloskeletal pada perawat. Korelasi antara kedua variabel memiliki kekuatan hubungan yang kuat dan positif yang artinya semakin tinggi skor beban kerja fisik maka keluhan muskuloskeletal pada perawat akan semakin meningkat.

Peneliti berharap hasil penelitian ini dapat menambah pengetahuan dan memotivasi perawat untuk menerapkan standar operasional prosedur dengan sikap ergonomi yang sesuai standar dalam melakukan asuhan keperawatan agar beban kerja fisik dan keluhan muskuloskeletal tidak meningkat. 


\section{DAFTAR PUSTAKA}

Desriana, M. L., \& Febi, K. K. (2017). Hubungan antara beban kerja dengan keluhan low back pain pada perawat di ruang rawat inap RS Bhayangkara Manado. Skripsi. Manado: Fakultas Kesehatan Masyarakat Universitas Sam Ratulangi

Elyas, Y. (2012). Gambaran tingkat risiko musculockeletal disorder pada perawat saat melakukan aktifitas kerja di ruang ICU PJT RSCM berdasarkan metode REBA. Jakarta: Fakultas Ilmu Keperawatan Univesitas Indonesia.

Hidayat, A. A.A. (2011). Metode penelitia keperawatan dan teknik analisis data. Jakarta: Salemba Medika.

Indriasari, J., Harmilah., Maryana. (2017). Hubungan beban kerja perawat ruang operasi dengan kejadia low back pain pada perawat di RSUD Kota Yogyakarta. Skripsi. Yogyakarta: Poltekes Kementrian Yogyakarta.

Kasmarani, M. (2012). Pengaruh beban kerja fisik dan mental terhadap stress kerja pada perawat di Instalasi Gawat Darurat RSUD Cianjur. Jurnal Kesehatan Masyarakat. 1(2).

Kemenkes RI. (2013). Profil kesehatan Indonesia tahun 2014. Jakarta: Kemenkes RI.

Kurniawidjaja L.M., Purnomo E, Maretri N dan Pujiriani. (2014). Pengendalian Risiko Ergonomi Kasus Low Back Pain pada
Perawat di Rumah Sakit. Jurnal Kesmas UI. Jakarta: 46(4).

Marinawati. (2016). Faktor-faktor yang berhubungan dengan keluhan muskuloskeletal padak pekerja pemanen kelapa sawit di Desa Rantau Kecamatan Rasau Kabupaten Tanjung Jabung Timur. Jurnal Stikes Prima, 5(2).

Marquis, B.L., \& Huston, C. J. (2010). Kepemimpinan dan Manajemen Keperawatan: Teori dan Aplikasi Edisi 4. Jakarta: EGC

Nursalam. (2013). Manajemen keperawatan: aplikasi dalam keperawatan profesional. Jakarta: Salemba Medika.

OSHA. (2013). Safe patient handling. Diakses dari http://www.osha.gov/SLTC/healt hcarefacilities/safepatienthandling .html.

Sekaaram, V., \& Ani, L. S. (2017). Prevalensi (MSDs) pada pengemudi angkutan umum di terminal mengwi, Kabupaten Badung-Bali. Intisari Sains Medis. 8(2), 118-124.

Siswiyanti, L. (2011). Beban kerja dan keluhan sistem muscoloskeletal pada pembatik tulis di Kelurahan Kalinyamat Wetan Kota Tegal. Skripsi. Universitas Pancasakti Tegal.

Sudiajeng, L. (2014). Kesehatan keselamatan kerja dan produktivitas. Surakarta: UNIBA Press.

Tarwaka. (2014). Keselamatan dan kesehatan kerja: manajemen dan implementasi $\mathrm{K} 3$ di tempat kerja. Surakarta: Harapan Press. 